\title{
Analysis of the association between Malaysian pre- university entry level CGPA and final year examination result in a medical programme
}

\author{
Omar, E. \& Sudi, L.S. \\ Universiti Teknologi MARA, Malaysia
}

\section{Background:}

Pre-university courses' cumulative grade point average (cGPA) constitute one of the criteria for acceptance into a medical programme in Malaysia. Locally grown preuniversity programmes include the Matriculation program, Sijil Tinggi Pelajaran Malaysia (STPM) and University-based Asasi Sains courses. Students from these courses are the main feeder to the Universiti Teknologi MARA's (UiTM's) Medical programme. Recently, there has been a suggestion to use an additional admissions test on top of the current entry criteria to enhance selection into medical schools. In addition, the published cGPA cut off point for entry needs scrutiny as the Faculty embarks on additional student selection scheme such as the multiple mini interview (MMI) method. Recent data on the association between Malaysian preuniversity programme cGPA and final year examination result is scant. The aim of this study is to investigate the association between preuniversity cGPA and final year examination result in a medical programme.

\section{Method:}

A cross-sectional study was conducted. Students' Preuniversity cGPA data and their respective final year examination marks were retrieved from the files of the academic office, Faculty of Medicine, Universiti Teknologi MARA. The cGPA data was divided into high and low values and subsequently analysed against the final year examination results. Non-parametric tests were used (the data was not normally distributed).

\section{Results:}

A total of 387 students were included in the analysis. The average preuniversity course's entry cGPA is 3.94. Higher cGPA value was significantly associated with good performance in the final year examination $(\mathrm{p}<0.05)$. All those who obtained grade $A$ at final examination had a cGPA of 4.0 at entry. While 3 out of 5 failures had a cGPA of 3.51 .

\section{Conclusion:}

High cGPA of Malaysian Preuniversity course at entry is significantly associated with high performance in the final year programme.

Keywords: Standard and governance 